\title{
BMJ Global Health Impact of zero-mark-up medicines policy on hospital revenue structure: a panel data analysis of 136 public tertiary hospitals in China, 2012-2020
}

\author{
Hanchao Cheng, Yuou Zhang, Jing Sun (D) , Yuanli Liu
}

To cite: Cheng $\mathrm{H}$, Zhang $\mathrm{Y}$, Sun J, et al. Impact of zeromark-up medicines policy on hospital revenue structure: a panel data analysis of 136 public tertiary hospitals in China, 2012-2020. BMJ Global Health 2021;6:e007089. doi:10.1136/ bmjgh-2021-007089

\section{Handling editor Lei Si}

- Additional supplemental material is published online only. To view, please visit the journal online (http://dx.doi.org/10. 1136/bmjgh-2021-007089)

Received 4 August 2021 Accepted 11 October 2021

\section{Check for updates}

\section{(c) Author(s) (or their} employer(s)) 2021. Re-use permitted under CC BY-NC. No commercial re-use. See rights and permissions. Published by BMJ

School of Health Policy and Management, Chinese Academy of Medical Sciences \& Peking Union Medical College, Beijing, China

Correspondence to

Professor Jing Sun;

sunjing@sph.pumc.edu.cn

\section{ABSTRACT}

Objective To quantify the overall and dynamic effects of the implementation of the zero-mark-up medicines policy on the proportionate revenue generated from medicines, medical services and government subsidies at Chinese tertiary public hospitals.

Methods The revenue data of 136 tertiary public hospitals from 2012 to 2020 and the implementation-time framework of zero-mark-up medicines policy of these hospitals were obtained from the institutional survey of the third-party evaluation of the China Healthcare Improvement Initiative. The study adopted the time-varying differencein-differences method and combined it with the event study approach to estimate the effects of the zero-mark-up medicines policy.

Results Following the implementation of the policy, the proportionate medicines revenue decreased by $3.23 \%$ $(p<0.001)$; the proportionate medical services revenue increased by $3.48 \%(p=0.001)$; and the difference in the proportionate government subsidies revenue was not significant. In the year of implementation, the proportion of revenue generated from medicines decreased by $7.76 \%(p=0.0148)$; and that from medical services increased by $8.62 \%(p=0.0167)$. The effect of the policy gradually strengthened thereafter. In 2020, the sixth year after some hospitals started the implementation of the policy, the share of revenue generated from medicines decreased the most by $18.43 \%(p=0.0151)$, and that generated from medical services increased the most by $15.29 \%(p=0.0219)$. The share of revenue generated from government subsidies increased by $2 \%-5 \%$ in the second, third, fifth and sixth years following implementation $(p<0.05)$.

Conclusions Although the policy goal of adjusting hospital revenue structure has been achieved, the findings were insufficient to conclude whether the policy goal of establishing a scientific compensation mechanism was met by increasing the price of medical services and government input. Additionally, whether there was an unexpected policy effect requires further analysis.

\section{INTRODUCTION}

Since the beginning of the opening-up policy until 2012, the proportion of pharmaceutical

\section{Key questions}

What is already known?

- Existing evidence of the impact of the zero-mark-up medicines policy on the revenue of public hospitals in China mainly includes a small number of sample hospitals focused on one specific area; only a limited number of large-scale studies have targeted the county public hospitals in rural areas, and no study has targeted the urban public hospitals at the national level.

What are the new findings?

- To our knowledge, this is the first study that targeted a nationwide sample of public hospitals across 31 provinces of China and generated additional evidence about the impact of the zero-mark-up medicines policy based on the quasi-experimental method.

What do the new findings imply?

- Although the policy goal of adjusting hospital revenue structure has been achieved, the decrease in proportionate medicines revenue and the increase in proportionate medical service revenue do not necessarily mean that a scientific compensation mechanism has been established.

expenditure to total health expenditure in China has remained above $40 \%$, much higher than the overall level of $20 \%$ of the Organisation for Economic Cooperation and Development countries for a long time. ${ }^{12}$ Chinese public hospitals relied on revenue generated from medicines to maintain operation. One important reason behind this was the long-time low-pricing policy of medical service, which has been implemented in the planned economy period and has been far below the real cost. Conversely, there was a long-time shortfall in government subsidy to public hospitals. ${ }^{3}{ }^{4}$ To maintain the operation of public hospitals, the government allowed public hospitals to add no more than $15 \%$ mark-up on medicines 
dispensed from hospital pharmacies and allowed pharmaceutical suppliers to give no more than a $5 \%$ discount to public hospitals. ${ }^{5}$ However, during the implementation of these policies, to generate more revenue, public hospitals formed hidden transactions with pharmaceutical suppliers, which led to the failure of the normal mechanism of price competition. The real mark-up on medicines dispensed by public hospitals used to be more than $40 \%{ }^{6}$ Public hospitals also allotted various revenue generation tasks to individual doctors, which drove overprescriptions and preference for highly priced medicines. ${ }^{7}$

To abolish the reliance of public hospitals on the revenue generated from medicines, China started to implement the zero-mark-up medicines policy (hereafter referred as 'the policy') and its supporting policies since 2009. The policy aimed to shift the compensation mechanism of public hospitals from three financing sources (medicines, medical services and government subsidies) to two financing sources (medical services and government subsidy). The adjustment of the compensation mechanism was intended to change the financial operation of public hospitals concerning heavy reliance on revenue generated from medicines. The core contents of the policy were removal of mark-up on medicines, dispensing of medicines (except herbal medicines) at the procurement price to patients and strengthening of government subsidy. Pricing reform of medical services and refined hospital management to control the cost internally were additional components of the policy. ${ }^{89}$ The policy was implemented across China in a stepwise manner. It was implemented first in public community and township healthcare centres in 2009 and then expanded to county public hospitals during 2012-2014. Urban public hospitals started to implement the policy since 2014. By the end of September 2017, all Chinese public health facilities implemented this policy. ${ }^{10-14}$ This study targeted the policy implemented in urban public hospitals. The analyses were based on the revenue data collected through the facility surveys of the third-party evaluation of China Healthcare Improvement Initiative conducted during 2016-2021. We quantified the changes in the key revenue structure of medicines, medical services and government subsidies of 136 urban tertiary public hospitals across the country before and after the implementation of the policy. The study aimed to generate evidence for judging whether the policy goal of "establishing a rational compensation mechanism in public hospitals, adjusting their revenue structure, and changing their operation mechanism of relying on revenue generated from medicines' was achieved.

\section{METHODS}

\section{Setting and participants}

This study targeted 136 urban tertiary public hospitals across 31 provinces in China. We selected at least one general hospital, one traditional Chinese medicine (TCM) hospital, and one maternal and child health (MCH) hospital from each province, except Tibet, where only one general hospital and one TCM hospital were selected. All hospitals managed by the National Health Commission (NHC) were included (including general hospitals, TCM hospitals and specialised hospitals other than MCH hospitals).

\section{Data source}

Data were collected through the facility surveys of the thirdparty evaluation of China Healthcare Improvement Initiative carried out in January 2016, 2017 and 2018, and in February 2019 and 2021. Data that were directly extracted from the financial settlement system of the hospital health information system were (1) the annual amount of revenue generated from outpatient care and inpatient care, respectively; (2) the annual amount of revenue generated from medicines of outpatient care and inpatient care, respectively; and (3) the annual amount of government subsidy revenue. We combined the annual amount of total revenue generated from outpatient care and inpatient care. We also combined the annual amount of medicines revenue generated from outpatient care and inpatient care. We then subtracted the combined annual medicines revenue from the combined total annual revenue and obtained the annual medical services revenue (in total amount, not in detailed components, excluding medicines). In the Chinese healthcare settings, fees of consultation, examination and test, surgery, nursing, bed, disposable medical materials and medicines, as well as government subsidy are the key sources of revenue for public hospitals. A part of the revenue data of three sample hospitals was not available.

\section{Policy implementation}

The 136 sample hospitals implemented the policy progressively, starting in different years from 2014 to 2017. Of these, 117 hospitals started the implementation during a month from February to October, and 19 hospitals started in the month of December. We defined the status of hospitals as 'implemented' in the year when they started to implement the policy in a month from February to October, and the status of those as 'non-implemented' in the year when they started to implement the policy in the month of December. The status of non-implemented was shifted to implemented in the following year. Except for a few sample hospitals that implemented the policy as pilots in their respective provinces, most of the sample hospitals started the implementation at the same time as the other hospitals did in the same province. The number of sample hospitals and the distributions of the types, locations and affiliations of the sample hospitals are presented in online supplemental annex 1 .

\section{Measurements}

1. Proportionate medicines revenue $=$ annual medicines revenue/ (annual medicines revenue +annual medical service revenue +annual government subsidy) $\times 100 \%$.

2. Proportionate medical service revenue (including consultation, examination and test, surgery, nursing, bed, disposable medical materials, excluding medicines revenue $)=$ annual medical service revenue $/$ an- 
nual medicines revenue +annual medical service revenue +annual government subsidy) $\times 100 \%$.

3. Proportionate government subsidy=annual government subsidy/(annual medicines revenue tannual medical service revenue +annual government subsidy) $\times 100 \%$.

4. Overall effect of the policy on proportionate revenue $(\%)$ : overall change in the proportionate revenue between the sample hospitals with implemented and non-implemented status during the study period (2012-2020).

5 . Dynamic effect of the policy on proportionate revenue $(\%)$ : changes in the proportionate revenues of the sample hospitals in their respective policy adoption years (2014-2017) or 1-6 years after the policy adoption (2015-2020). The year 2012 was set as a reference, which was 2 years ahead of the year when the first sample hospital adopted the policy, and 5 years ahead of the year when the largest number of sample hospitals adopted the policy.

\section{Study design}

We adopted the time-varying difference-in-differences (DID) method to estimate the policy effect on the proportionate revenues of medicines, medical services and government subsidies, based on the 9-year panel data and stepwise policy implementation time framework of 136 sample hospitals from 2012 to 2020. The DID method has been widely used in policy effect estimates through comparisons between groups with 'implemented' and 'non-implemented' status before and after the implementation. The time-varying DID method converts the dummy variables of the interaction term of the traditional DID method into multiple implementation statuses, which enables an identical dummy variable for all observations at any time. ${ }^{1516}$ Based on the timevarying DID method, we adopted a hospital-level fixed-effect model to control for the effect of the time-invariant characteristics of individual hospitals on the outcome measure. We also added a time variable to the DID model to fit the twoway fixed-effect model, which controlled the effect of the time-varying factors (eg, national economic environment) on outcome measure. ${ }^{17}$

Considering that the policy effect might change after different lengths of time of implementation, we combined the DID method with the event study approach (ESA) and set the dummy variable of relative length of time of implementation to estimate the dynamic effect of the policy in the year of implementation and different years after the implementation. ${ }^{18-20}$ Given that the COVID-19 pandemic in 2020 might also have had an impact on the hospital revenue structure, and all 136 sample hospitals had already experienced at least 2 years of implementation of the policy until 2019, we compared the median revenue structures of 136 sample hospitals. We set the level of statistical significance level at $\alpha=0.05$ and defined a statistically significant difference when the $p$ value is $<0.05$. Data management and analyses were performed using Excel V.2016 and Stata V.16.

\section{Statistical analysis}

We fitted the baseline pooled regression model (model 1) by pooling the proportionate revenue data of the 136 sample hospitals during 9 years. We divided the 136 hospitals into implemented and non-implemented groups based on the year in which they started implementing the policy. Type of hospital (general, TCM, MCH and specialised hospital other than MCH), affiliation of hospital (affiliated to central government and affiliated to local government), location of hospital (eastern, central and western areas) and identification coding of hospital (coded as 1-31) were included in the model as covariates. Considering that there might be autocorrelations in the measurements of individual hospitals across different time periods, we adopted hospital ID as the cluster variable and used the robust $\mathrm{SE}$ of the cluster to control the autocorrelations ${ }^{17}$ as follows:

$$
y_{i t}=\alpha+\lambda * \text { treat }_{i t}+\beta X_{i t}+\varepsilon_{i t} \quad(\operatorname{model} 1)
$$

where $y_{i t}$ indicates the proportionate venue of sample hospital $i$ in year $t$, treat $_{i t}$ is the status of he sample hospital $i$ in year $t$. We defined the status of 'implemented' as 1 and 'non-implemented' as $0 . \lambda$ denotes the marginal effect of the policy; $X_{i t}$ denotes the control variables, including the type of hospital, affiliation of hospital and location of the hospital. $\alpha$ is the constant term, and $\varepsilon_{i t}$ are random terms.

Although the covariates might help to reduce the confounding of the characteristics of hospitals, the unobserved characteristics of hospitals could not be controlled. To further reduce the confounding of the unobserved characteristics of hospitals, we adopted a hospital-level fixed-effect time-varying DID model (model 2) ${ }^{17}$ and calculated the cluster-robust SE. The new model is as follows:

$$
y_{i t}=\alpha+\lambda * \text { treat }_{i t}+\mu_{i}+\varepsilon_{i t} \quad(\text { model } 2)
$$

Compared with model 1 , the term hospital-specific characters $\mu_{i}$ in model 2 helped to control the confounding effect of the time-invariant characteristics of the hospital. The type of hospital, affiliation of hospital and location of hospital are the inherent characteristics of hospitals, which were already well controlled in the hospital-level, fixedeffect model. We removed these covariates in the hospitallevel, fixed-effect model to maintain the conciseness of the model. To further control for time-varying confounding factors, we adopted the hospital and time fixed-effect model ${ }^{1718}$ by including the time effect term $\gamma_{t}$ in model 2 to convert different years into dummy variables for inclusion in model 2. Cluster-robust SEs were also calculated. The new model is as follows:

$$
y_{i t}=\alpha+\lambda * \text { treat }_{i t}+\mu_{i}+\gamma_{t}+\varepsilon_{i t} \quad(\text { model } 3)
$$

Considering that there might be a legged policy effect in the real world, ${ }^{21}$ the initial effect might be small and the effect might be strengthened long after the implementation. To observe such varied policy effects across a time span, we added the length of implementation of the policy as dummy variable in model 3 and combined the timevarying DID method with ESA to estimate the dynamic effect of the policy, ${ }^{19}$ with the new model as follows: 


$$
y_{i t}=\alpha+\beta_{t-k} * D_{i(t-k)}+\mu_{i}+\varepsilon_{i t} \quad(\operatorname{model} 4)
$$

$D_{i(t-k)}$ denotes the length of policy implementation, and we subtracted the year $k$ when sample hospital $i$ started to implement the policy from year $t$ and obtained $D_{i(t-k)}$. For example, -1 denotes 1 year before the implementation; 0 denotes the starting year of the implementation; 1 denotes 1 year after the implementation; and so on. $\beta_{t-k}$ indicates the policy effect $t-k$ years after the implementation of the policy. Among the 136 sample hospitals, the earliest year in which implementation was started was 2014; the latest year was 2017; and our observation time was from 2012 to 2020. We were able to estimate the dynamic effect of the policy from the year of the implementation to 1-6 years after the implementation by comparing it with the status $1-5$ years before the implementation (the default comparison was the earliest year before the implementation, that is, 5 years before the implementation in 2012).

We performed the Wilcoxon signed-rank tests to compare the median proportionate revenues of the 136 sample hospitals between 2019 and 2020 .

\section{RESULTS}

\section{Stepwise implementation of the policy at 136 sample hospitals}

Among the 136 sample hospitals, one general hospital, one TCM hospital and one MCH hospital from Zhejiang province started implementing the policy in 2014, the earliest year. Fifteen sample hospitals implemented the policy in 2015, covering the provinces of Inner Mongolia, Ningxia, Fujian, Jiangsu and Anhui. Eighteen sample hospitals implemented the policy in 2016, covering the provinces of Shandong, Guizhou, Qinghai, Hunan and Jilin. The other 100 sample hospitals implemented the policy in 2017 (figure 1).

\section{Estimation of policy effect on the proportionate revenue Overall effect estimation}

As presented in table 1, owing to the unavailability of a part of data of three sample hospitals, there were a total of 1210 observations for each outcome measurement. The results of the pooled regression model (model 1) showed that, compared with the sample hospitals with the 'non-implemented' status, overall, the proportionate medicines revenue of those with the 'implemented'status decreased by $9.16 \%(\mathrm{p}<0.001)$; the proportionate medical service revenue of those with the 'implemented' status increased by $8.86 \%(\mathrm{p}<0.001)$; and the change in the proportionate government subsidy revenue was not statistically significant $(p>0.05)$. The results of the hospitallevel fixed-effect model (model 2) were close to those of model 1; the proportionate medicines revenue decreased by $9.12 \%(p<0.001)$; the proportionate medical service revenue increased by $8.79 \%(\mathrm{p}<0.001)$; and the change in the proportionate government subsidy revenue was not statistically significant $(p>0.05)$. The results of the two-way fixed-effect model (model 3) showed a 3.23\% $(\mathrm{p}<0.001)$ reduction in the proportionate medicines revenue, $3.48 \%(\mathrm{p}=0.001)$ reduction in proportionate medical service revenue and a change in the proportionate government subsidy revenue with no statistical significance $(p>0.05)$.

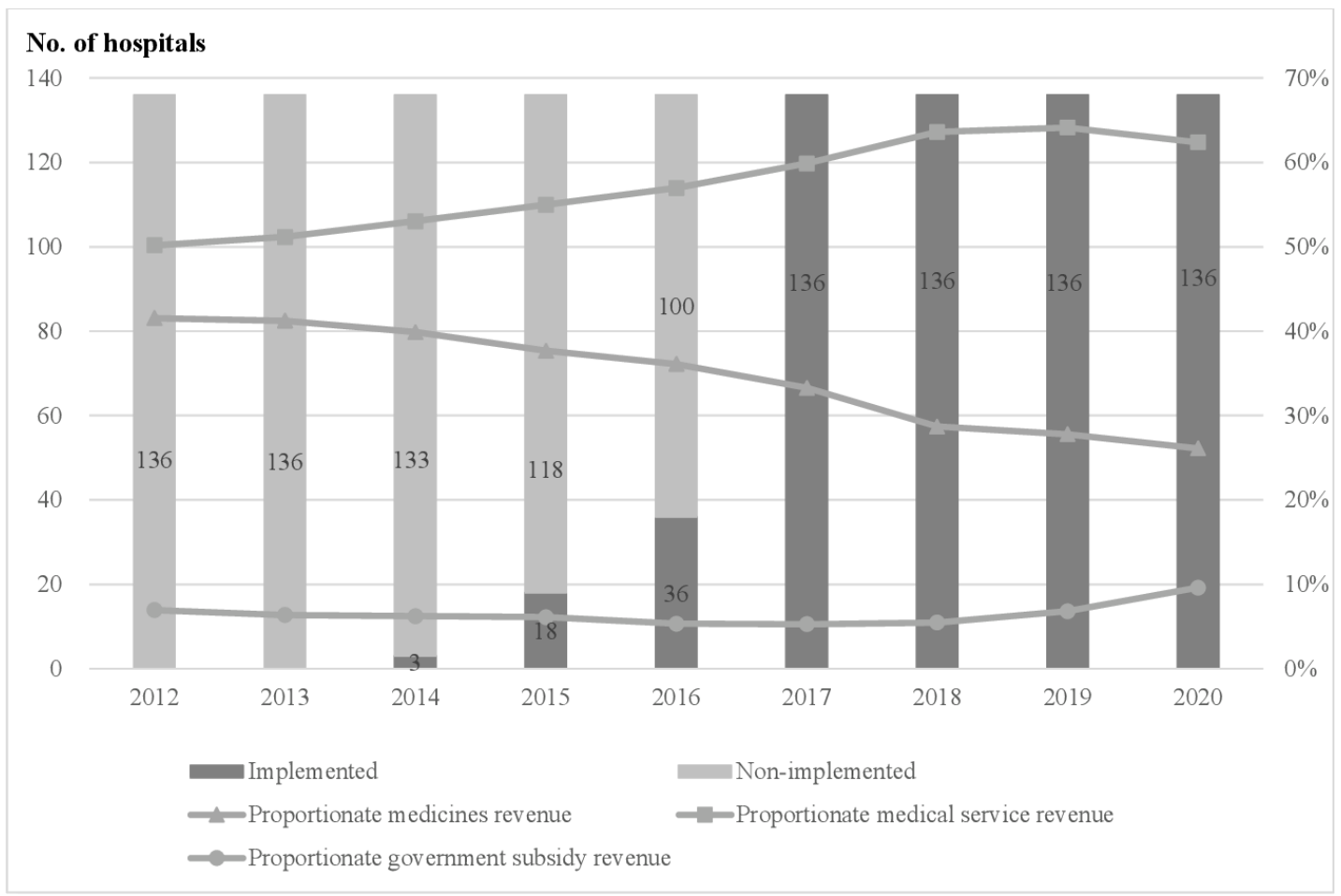

Figure 1 Stepwise implementation of the policy and median proportionate revenues of 136 sample hospitals (2012-2020). 
Table 1 Overall effect of the zero-mark-up medicines policy (2012-2020)

\begin{tabular}{|c|c|c|c|c|c|}
\hline Model & $\begin{array}{l}\text { Measurement } \\
\left(y_{\mathrm{it}}\right)\end{array}$ & Observations (n) & $\begin{array}{l}\text { Coefficient } \\
(\lambda)\end{array}$ & $\begin{array}{l}\text { Cluster-robust } \\
\text { SE }\end{array}$ & $P$ value \\
\hline \multirow{3}{*}{$\begin{array}{l}\text { Pooled regression } \\
\text { model (model } 1 \text { ) }\end{array}$} & Proportionate medicines revenue & 1210 & -0.0916 & 0.0058 & $<0.001$ \\
\hline & $\begin{array}{l}\text { Proportionate medical service } \\
\text { revenue }\end{array}$ & 1210 & 0.0886 & 0.0064 & $<0.001$ \\
\hline & $\begin{array}{l}\text { Proportionate government } \\
\text { subsidy revenue }\end{array}$ & 1210 & 0.0030 & 0.0040 & 0.452 \\
\hline \multirow{3}{*}{$\begin{array}{l}\text { Hospital-level fixed- } \\
\text { effect model (model } \\
\text { 2) }\end{array}$} & Proportionate medicines revenue & 1210 & -0.0912 & 0.0057 & $<0.001$ \\
\hline & $\begin{array}{l}\text { Proportionate medical service } \\
\text { revenue }\end{array}$ & 1210 & 0.0879 & 0.0063 & $<0.001$ \\
\hline & $\begin{array}{l}\text { Proportionate government } \\
\text { subsidy revenue }\end{array}$ & 1210 & 0.0033 & 0.0039 & 0.398 \\
\hline \multirow{3}{*}{$\begin{array}{l}\text { Two-way fixed-effect } \\
\text { model (model 3) }\end{array}$} & Proportionate medicines revenue & 1210 & -0.0323 & 0.0086 & $<0.001$ \\
\hline & $\begin{array}{l}\text { Proportionate medical service } \\
\text { revenue }\end{array}$ & 1210 & 0.0348 & 0.0098 & 0.001 \\
\hline & $\begin{array}{l}\text { Proportionate government } \\
\text { subsidy revenue }\end{array}$ & 1210 & -0.0025 & 0.0076 & 0.740 \\
\hline
\end{tabular}

Dynamic effect estimation

The results of the time-varying DID method combined with the ESA based on the dynamic effect model (model 4) are presented in table 2 and figure 2 . In the year of starting the implementation of the policy, the proportionate medicines revenue decreased by $7.76 \%$ $(\mathrm{p}=0.0148)$, and the proportionate medical service revenue increased by $8.62 \%(p=0.0167)$. As the length of policy implementation increased, the dynamic effect of the policy strengthened. The dynamic effect reached the highest 6 years after the implementation, which led to the proportionate medicines revenue being reduced by $18.43 \% \quad(p=0.0151)$ and the proportionate medical service revenue being increased by $15.29 \%(p=0.0219)$. There was a $2 \%-5 \%$ increase in the proportionate government subsidy revenue 2-3 years and 5-6 years after implementation $(\mathrm{p}<0.05)$.

Compared with those in 2019, the median proportionate medicines revenue and the median medical service revenue of the 136 sample hospitals decreased by $1.68 \%(Z=-5.71, \mathrm{p}<0.001)$ and $1.75 \%(Z=-5.50, \mathrm{p}<0.001)$ in 2020, respectively, and the median proportionate government subsidy revenue increased by $2.8 \% \quad(Z=-7.21$, $\mathrm{p}<0.001)$.

\section{Sensitivity analysis}

The pooled regression model (model 1) regarded the panel data as cross-sectional data to perform OLS regression. The assumption of the aforementioned analysis was that there was no individual effect. We adopted the

Table 2 Dynamic effect of the zero-mark-up medicines policy (2012-2020)

\begin{tabular}{|c|c|c|c|c|}
\hline $\begin{array}{l}\text { Length of policy } \\
\text { implementation }\end{array}$ & Observations (n) & $\begin{array}{l}\text { Marginal effect on the } \\
\text { proportionate medicines } \\
\text { revenue }\end{array}$ & $\begin{array}{l}\text { Marginal effect on the } \\
\text { proportionate medical } \\
\text { service revenue }\end{array}$ & $\begin{array}{l}\text { Marginal effect on } \\
\text { the proportionate } \\
\text { government subsidy } \\
\text { revenue }\end{array}$ \\
\hline $\begin{array}{l}\text { The year of } \\
\text { implementation }\end{array}$ & 1210 & $-0.0776(0.0148)^{\star \star \star}$ & $0.0862(0.0167)^{\star \star \star}$ & $-0.0086(0.0116)$ \\
\hline $\begin{array}{l}1 \text { year after } \\
\text { implementation }\end{array}$ & 1210 & $-0.1065(0.0134)^{\star \star \star}$ & $0.1077(0.0151)^{\star \star \star}$ & $-0.0012(0.0118)$ \\
\hline $\begin{array}{l}2 \text { years after } \\
\text { implementation }\end{array}$ & 1210 & $-0.1304(0.0124)^{\star \star \star}$ & $0.1087(0.0136)^{\star \star \star}$ & $0.0216(0.0104)^{*}$ \\
\hline $\begin{array}{l}3 \text { years after } \\
\text { implementation }\end{array}$ & 1210 & $-0.1329(0.0108)^{\star \star \star}$ & $0.1126(0.0119)^{\star \star \star}$ & $0.0203(0.0089)^{\star}$ \\
\hline $\begin{array}{l}4 \text { years after } \\
\text { implementation }\end{array}$ & 324 & $-0.1415(0.0118)^{\star \star \star}$ & $0.1266(0.0135)^{\star \star \star}$ & $0.0149(0.0096)$ \\
\hline $\begin{array}{l}5 \text { years after } \\
\text { implementation }\end{array}$ & 162 & $-0.1694(0.0125)^{\star \star \star}$ & $0.1170(0.0213)^{\star \star \star}$ & $0.0524(0.0229)^{\star}$ \\
\hline $\begin{array}{l}6 \text { years after } \\
\text { implementation }\end{array}$ & 27 & $-0.1843(0.0151)^{\star \star \star}$ & $0.1529(0.0219)^{\star * \star}$ & $0.0314(0.0143)^{\star}$ \\
\hline
\end{tabular}

${ }^{*} \mathrm{P}<0.05,{ }^{* * *} \mathrm{P}<0.001$.

Cluster-robust SEs are within parentheses. 

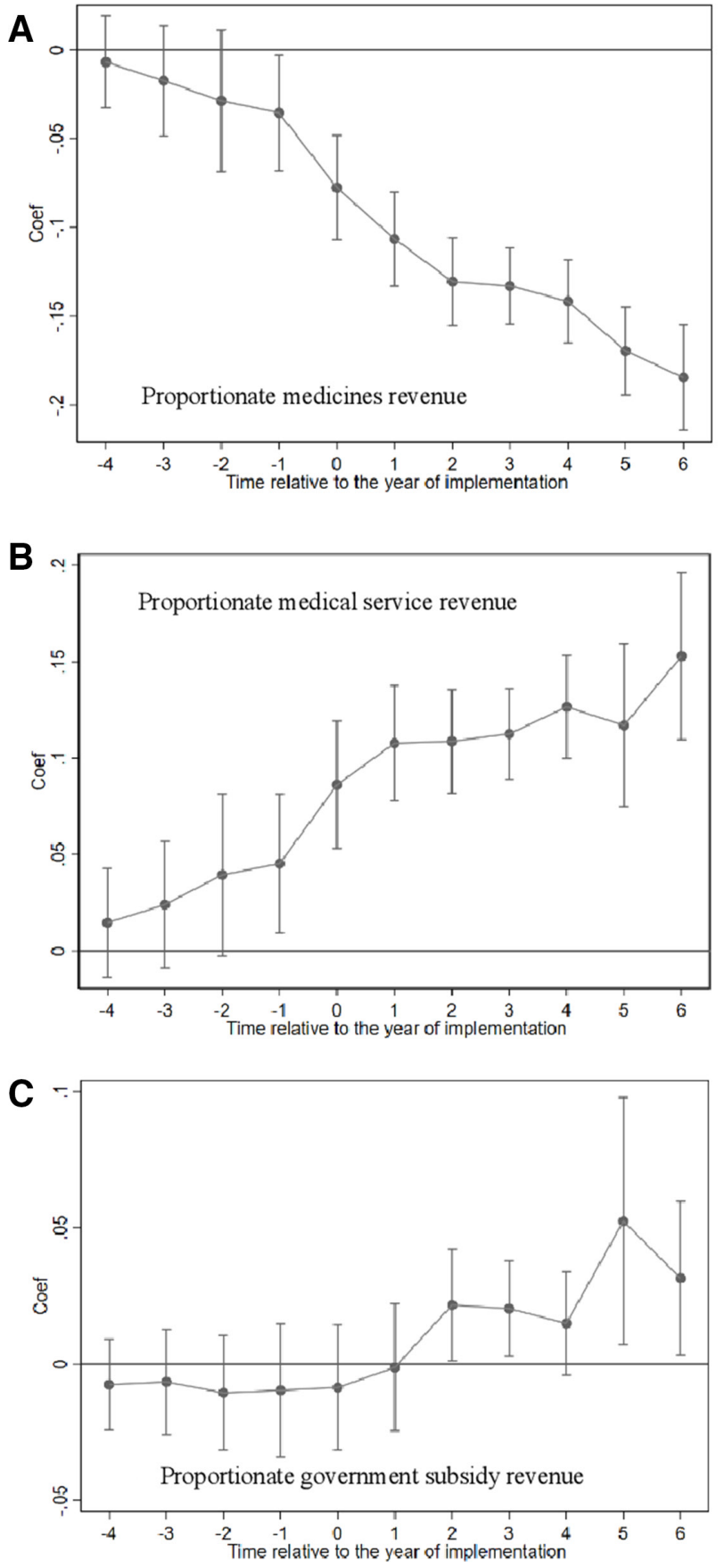

Figure 2 Dynamic effect of the zero-mark-up medicines policy (2012-2020).

least square dummy variable model (LSDV) to include the hospital identification code as a dummy variable in model 1 to test the individual effect of the sample hospitals. ${ }^{11}$ The results of the LSDV regression showed that, except for the omitted observations due to multicollinearity, all other sample hospitals had statistically significant differences compared with the controlled sample hospital (default as the hospital coded number 1). This indicates an individual hospital effect. The estimation based on model 1 might be biased and needed to adopt the hospital-level, fixed-effect model to reduce the individual effect of hospitals on the policy effect estimation.
The models adopted in this study were based on the DID method. The most important assumption of the DID method is the parallel assumption, that is, no statistically significant difference between the sample hospitals in the implemented and non-implemented group before implementation of the policy, or they had the same outcome measure trend. Considering that the earliest year of the sample hospitals to adopt the policy was 2014, we constructed two pseudo-implementation models based on model 3 by assuming that the implementation happened one or 2 years ahead. If the estimate of pseudo-implementation is different from 0 , the trends are not parallel, and the estimation based on model 3 is likely to be biased. ${ }^{18}$ As presented in online supplemental annex 2, the overall effect estimation of the pseudo-implementation on the proportionate medicines, medical service and government subsidy revenues had no statistical significance $(\mathrm{p}>0.05)$. This implies that the overall effect model met the parallel assumption. For the dynamic effect model, we checked the parallel assumption by comparing coefficient $\beta$ with $0 . \beta$ in model 4 is the effect estimation before the implementation. ${ }^{22}$ As presented in figure 2, for the proportionate medicines and medical service revenues, the $95 \%$ CI of coefficient $\beta$ for effect estimation 2-4 years ahead of the implementation was 0 . This indicated that there were parallel trends, 2 and more than 2 years ahead of the implementation. The effect estimations 1 year ahead of the implementation were $-0.0356(95 \% \mathrm{CI}-0.0682$ to $-0.0030, \mathrm{p}=0.033)$ and 0.0453 (95\% CI 0.0092 to $0.0813, \mathrm{p}=0.014)$, respectively. This implied that there were statistically significant differences in the proportionate medicines and medical service revenues between the hospitals in the implemented and non-implemented groups. The interpretation of dynamic effects should be prudent. To relax the parallel assumption, we included the province-specific time trend and region-specific time trend in model 4, allowed the sample hospitals in different provinces and (or) regions to have different outcome measure trends and controlled the time-varying confounding factors at the provincial and regional levels ${ }^{16}{ }^{18}$ in order to reduce the bias of the estimation. Coefficient $\beta$ for the effect estimation of proportionate government subsidy revenue for all years ahead of the implementation was around 0 , which indicated that the parallel trend assumption was met.

Models $3 \mathrm{a} / \mathrm{b}$ and $4 \mathrm{a} / \mathrm{b}$ (online supplemental annex 3,4 ) were fitted by adding the province-specific time trend term and the region-specific time trend term to the twoway fixed-effect overall effect model (model 3) and the dynamic effect model (model 4). The regression results of model $3 \mathrm{a} / \mathrm{b}$ and model 3 were very close to each other, which implied that the provincial and regional level time-varying confounding factors had little effect on the outcome measure, and the overall effect estimation based on model 3 was reliable. Comparing the regression results of model $4 \mathrm{a} / \mathrm{b}$ with that of model 4 , we found that controlling of the province-specific time trend and 
the region-specific time trend was helpful to minimise the estimation bias of the proportionate medicines and medical service revenues, respectively, due to the difference in the proportionate medicines and medical service revenues between the hospitals in the implemented and non-implemented groups 1 year ahead of the implementation. For the proportionate government subsidy revenue, we failed to obtain a consistent estimate after including the province-specific time trend term and the region-specific time trend term into the dynamic effect model.

We also conducted the subgroup analyses of the average treatment effect of the policy based on different types, locations and affiliations of the sample hospitals. The results are presented in online supplemental annex 5A-C, respectively, and they were generally consistent with each other; that is, the policy led to a reduction in the proportionate medicines revenue, an increase in the proportionate medical service revenues and no change in the proportionate government subsidy revenue. There were a few exceptions such as the impacts of the policy on reduction of proportionate medicines revenue and increase of proportionate medical service revenue were not statistically significant $(\mathrm{p}=0.255$ and $\mathrm{p}=0.097)$.

\section{DISCUSSION}

This study adopted the time-varying DID method to estimate the overall effect of the policy on the proportionate medicines, medical service and government subsidy revenues during 2012-2020 based on the hospital level and time two-way, fixed-effect model. The study also combined the DID method with the ESA to estimate the dynamic effects of the aforementioned outcome measures. Except that the subgroup analyses based on the location of the sample hospitals did not reveal statistically significant changes in the revenue structure in western region, the results of all the other subgroups drew a consistent conclusion. This might be associated with the fact that the number of observation in the western region was small (377). Overall, the findings of this study, including the respective significant decrease and increase in the proportionate medicines revenue and proportionate medical service revenue, were consistent with each other. The proportionate government subsidy revenue slightly increased sometime after the implementation but generally had no statistically significant difference during the observation period. These findings are consistent with the findings of two systematic reviews or meta-analysis. ${ }^{23} 24$ Shi and colleagues ${ }^{18}$ studied county TCM hospitals across rural China. Jiang and colleagues ${ }^{25}$ analysed county general and county TCM hospitals in rural Shandong province. Wang and colleagues ${ }^{26}$ targeted urban tertiary general hospitals, TCM hospitals and specialised hospitals in Shanghai. Yan and colleagues ${ }^{27}$ measured urban tertiary and secondary hospitals in Shaanxi province. All studies found a reduction in the proportionate medicines revenue.
Medicines, medical service and government subsidies were the main sources of revenue for public hospitals. When the proportionate government subsidy revenue was generally unchanged, the proportionate medicines and medical service revenues were interdependent. From 2012 to 2020, the overall effect of the policy on the proportionate medicines revenue of 136 tertiary public hospitals across the country was a reduction of $3.23 \%$, which was lower than the increase of $3.48 \%$ from the proportionate medical service revenue. This implied that the increase in medical service revenue was faster than the reduction in medicines revenue, and the former increase was a major contributor to the change in the public hospital revenue structure (table 1). The dynamic effect estimate, as presented in table 2 , showed that the reduction effect on the proportionate medicines revenue $(7.76 \%-10.65 \%)$ was lower than the increasing effect on the proportionate medical service revenue $(8.62 \%-10.77 \%)$ in the year of implementation and shortly after the implementation. In a longer run, the reduction effect on the proportionate medicines revenue $(13.4 \%-18.43 \%)$ was higher than the increasing effect on the proportionate medical service revenue $(10.87 \%-15.29 \%)$. This implies that in the early stage of the implementation of the policy, the increase in medical service revenue was the key contributor to the revenue structure change at public hospitals. With the full and longer implementation of the policy, the key contributor to the revenue structure change at public hospitals shifted to the reduction in medicines revenue.

We assumed that in the early stage of the policy implementation, rising medical service revenue might be associated with the supporting policy of the zero-mark-up medicines policy, that is, increased pricing of labourintensive medical services. However, existing evidence ${ }^{28}$ showed that, by 2020, the medical service pricing schedules of most of the 31 provinces were not updated following the national medical service pricing guidelines. This implies that increased pricing of labour-intensive medical service might not occur in most provinces. Thus, we had to consider other drivers. Given that medical service revenue includes revenue generated from disposable medical materials, tests and examinations with expensive medical equipment, the policy may drive the change in medical behaviour, that is, unnecessary highly priced disposable medical materials with mark-ups, tests and examinations with expensive medical equipment. There are several studies about the impact of the policy on the tertiary and secondary hospitals of Beijing in 2017 which found that the expenditures of inpatients on highly priced disposable medical materials, as well as those of outpatients on test and examination with expensive medical equipment, increased significantly. ${ }^{29}$ Moreover, the proportionate expenditures of outpatients on test and examination with expensive medical equipment at an oncology specialised hospital significantly increased. ${ }^{30} 31$ This indicated that some public hospitals intended to compensate for the missing revenue from medicines due to implementation of the policy by inflating the use of 
highly priced disposable medical materials, unnecessary tests and examinations with expensive medical equipment. ${ }^{32}$ Whether these findings can be extrapolated to other areas outside Beijing requires further study. The rising medical service revenue due to such unexpected medical behaviour changes and overconsumption of medical resources has become a key contributor to the revenue structure change at public hospitals, thereby reducing the proportionate medicines revenue. Thus, interference in the estimation of policy effect and such a reduction in medicines revenue and revenue structure change were not the original expected intentions of the policy.

The estimated effects based on the different models varied. The regression result of model 1 was similar to that of model 2, implying that hospital individual effects existed. As the sample hospitals were all urban tertiary public hospitals, such hospital individual effects did not significantly affect the estimation. The absolute changes in proportionate medicines and medical service revenues estimated based on model 3 were smaller than those based on models 1 and 2. This implies that the timevarying inherent confounding factors for the proportionate medicines and medical service revenue affected the estimations based on models 1 and 2. When such inherent confounding factors were eliminated in model 3 , the estimation was closer to the real overall effect. The overall effect estimations based on models 1-3 for the proportionate government subsidy revenue were all with no statistical significance, which indicated that the proportionate government subsidy revenue did not increase significantly during the observation time overall.

The policy was implemented stepwise in urban public hospitals across the country, starting with four waves of pilots. ${ }^{33-36}$ The pilots were implemented in parallel across the eastern, central and western areas. The piloted cities were selected from those with a middle level of economic and social development, demographic and scale of public hospitals within their jurisdictions. After the implementation of the policy, the aforementioned characteristics of the piloted areas did not change. Thus, the selection bias was minimised. However, the difference between the provinces that implemented the policy stepwise, and the fact that the 136 sample hospitals are all the ones with the highest quality and reputation in their respective specialisations in each province, may restrict extrapolation of the results of this study.

A parallel trend test of the estimation based on the dynamic effect model showed that coefficient $\beta$ had no statistical significance 1 year before the implementation for the estimation of proportionate medicines and medical service revenues (figure 2A,B). This indicated the absence of strict parallels might be associated with the following reasons. The policy was first implemented in primary care facilities since $2009^{78}$ and expanded from county public hospitals in rural areas to urban public hospitals. Urban tertiary public hospitals were the last group to implement the policy. Medical behaviours in these hospitals might change through the spill-over effect of the policy implemented in the neighbouring hospitals, provinces and regions, and are already prepared for the upcoming implementation. The parallel trend assumption could be relaxed by controlling the provincespecific time trend and the region-specific time trend in the dynamic effect model. The sensitivity analysis results showed that the dynamic effects on the proportionate medicines and medical service revenues based on model 4 might be overestimated. There might be provinciallevel, time-varying confounding factors for the dynamic effect estimation of the proportionate medicines revenue, and there might be regional-level time-varying confounding factors in the dynamic effect estimation of the proportionate medical service revenue. The dynamic effect model failed to make an unbiased estimation of the proportionate government subsidy revenue. There is a need to further analyse and test other time-varying factors that affect government subsidy revenue.

The results of both the average treatment effect and dynamic treatment effect estimations (more than 2 years after the implementation of the policy) did not reveal a statistically significant increase in the proportionate government subsidy revenue. Neither the average treatment effect estimation nor the dynamic treatment effect estimation could specifically reflect the changes in revenue structure between 2019 and 2020. By comparing the median revenue structure of the 136 sample hospitals, we found that the median proportionate government subsidy revenue of the hospitals in 2020 was statistically significantly higher than that of the hospitals in 2019. This was in line with the evidence that, although the COVID-19 pandemic in 2020 led to dramatic reductions in outpatient visit and hospitalisation, as well as total revenue of public hospitals in China, government subsidy was generally strengthened. ${ }^{37}$

This study had several limitations. First, the study adopted a hospital-level, fixed-effect model which controlled the time-invariant inherent characteristics of the sample hospitals to reduce selection bias. However, confounding variables such as the number of outpatient visits and hospitalisations, hospital beds, staff and fixed assets could not be eliminated through the hospital-level fixed effect. These variables should be included in the regression model. An existing study that estimated the policy effect on county TCM hospitals across the country ${ }^{18}$ found that the annual growth rates of the aforementioned variables did not have significant effects on the proportionate medicines revenue. Although this study did not measure the aforementioned variables, it might not yield an unacceptable biased estimation. However, it would be valuable for future studies to include the aforementioned variables and to analyse how the policy changed the absolute amount of hospital revenues like the study conducted by Zhang and colleagues ${ }^{38}$ in urban secondary and tertiary public hospitals across the country based on the macroeconomic data of 31 provinces. The impact on hospital revenue might be associated with changes in incentives of doctors and hospitals and has 
implications with respect to quality of care after implementation of the policy. Second, this study focused only on medicines revenue, medical service revenue and government subsidy revenue; the sum of these revenues is not the real total revenue of Chinese public hospitals. Revenue from the government earmarked for scientific research and other minor revenues have been neglected. ${ }^{2}$ In addition, the data on proportionate government subsidy revenue were distributed with positive skewness. Considering that the sample size was large enough, we did not perform the logarithmic transformation on the proportionate revenues to adjust for right-skewed data. We neglected the potential effect of the skewed distribution on the estimation, in order to draw the regression results that are easily interpreted in the differences of the proportionate revenues. Finally, medical service revenue in Chinese tertiary public hospitals covers revenue generated from disposable medical materials, tests and examinations, and so on. Because the data used by this study were collected from completed surveys, the restriction on data availability did not allow us to collect more detailed data on medical service revenue. Therefore, this study did not analyse whether the significant increase in proportionate medical service revenue and the change in revenue structure were associated with overconsumption of highly priced disposable medical materials and unnecessary tests and examinations. This study did not analyse the potential impact of the zero-mark-up, highly priced disposable medial materials policy implemented in public hospitals during 2018-2020. ${ }^{39}$

\section{CONCLUSIONS}

The policy implemented in 136 tertiary public hospitals across the country was associated with a continuous reduction in the proportionate medicines revenue, a continuous rise in the proportionate medical service revenue and a change in the proportionate government subsidy revenue which was not significant. Based on the findings of this study, we concluded that the policy achieved one of its set objectives of adjusting the revenue structure of public hospitals. We could not conclude whether the other set goal of establishing a rational compensation mechanism for public hospitals by raising labour-intensive medical service pricing and increasing the government subsidy was achieved. Additionally, whether there has been any unexpected effect of the policy on public hospitals requires further analysis and evaluation.

Contributors JS and YL made the initial conception of this study. HC and YZ managed the data extracted from the facility surveys of the third-party evaluation of China Healthcare Improvement Initiative 2016-2021. HC performed the statistical analyses. $\mathrm{HC}$ and YZ made the initial data interpretations. HC drafted the first version of manuscript. All authors made contributions to the revision and approval of the manuscript. YL is responsible for the overall content as the guarantor.

Funding The surveys were funded by the National Health Commission Thirdparty Evaluation of China Healthcare Improvement Initiative 2016-2021, while the writing of this manuscript received no funding.

Competing interests None declared.

Patient consent for publication Not applicable.
Provenance and peer review Not commissioned; externally peer reviewed.

Data availability statement Data are available upon reasonable request.

Supplemental material This content has been supplied by the author(s). It has not been vetted by BMJ Publishing Group Limited (BMJ) and may not have been peer-reviewed. Any opinions or recommendations discussed are solely those of the author(s) and are not endorsed by BMJ. BMJ disclaims all liability and responsibility arising from any reliance placed on the content. Where the content includes any translated material, BMJ does not warrant the accuracy and reliability of the translations (including but not limited to local regulations, clinical guidelines, terminology, drug names and drug dosages), and is not responsible for any error and/or omissions arising from translation and adaptation or otherwise.

Open access This is an open access article distributed in accordance with the Creative Commons Attribution Non Commercial (CC BY-NC 4.0) license, which permits others to distribute, remix, adapt, build upon this work non-commercially, and license their derivative works on different terms, provided the original work is properly cited, appropriate credit is given, any changes made indicated, and the use is non-commercial. See: http://creativecommons.org/licenses/by-nc/4.0/.

ORCID iD

Jing Sun http://orcid.org/0000-0002-4646-1174

\section{REFERENCES}

1 Mossialos E, Ge Y, Hu J. Pharmaceutical policy in China: challenges and opportunities for the reform. Beijing: China Development Publishing House, 2017.

2 China. Health statistics Yearbook 2013. Beijing: China Union Medical University Publishing House, 2013.

3 Liu J, Wan X. Government subsidy mechanism of Chinese public hospitals. Chin Health Econ 2009;28:31-4.

4 Yin C. Reform pathway of public hospital compensation mechanism under the zero mark-up medicines policy-the case of Ningbo. Zhejiang: Zhejiang University Publishing House, 2018.

5 Former State Reform and Planning Commission of China. The announcement of implementing the medicines pricing regulation document No. 624 of 1998, 1998.

6 Zhang M, Bian Y. Review of the impact of medicines pricing and mark-up policies in Chinese public hospitals. Chin Health Serv Manag 2007;23:465-6.

$7 \mathrm{Hu}$ J, Mossialos E. Pharmaceutical pricing and reimbursement in China: when the whole is less than the sum of its parts. Health Policy 2016;120:519-34.

8 Wen Q, Liu Q, Gao W. Revenue and medical expenditure in public hospital after implementation of the zero mark-up policy. Chin Hosp manage 2018;38:4-7.

9 The Government of China. The implementation plan of the National health system reform (2009-2011), 2009. Available: http://www.gov. cn/zwgk/2009-04/07/content_1279256.htm

10 The State Council Office. The announcement of the implementation plan for deepening the National health system reform 2012, 2012. Available: http://www.gov.cn/xxgk/pub/govpublic/mrlm/201204/ t20120417_65028.html

11 The Government of China. The announcement of the state Council office for comprehensive reforms in County Hospital, 2012. Available: http://www.gov.cn/zwgk/2012-06/14/content_2161153. htm

12 The State Council Office. The announcement of releasing the 2014 summary and 2015 work plan for deepening the National health system reform, 2015. Available: http://www.gov.cn/zhengce/content/ 2015-05/09/content_9716.htm

13 The Government of China. The Guideline for comprehensive reform in urban public hospitals announced by the state Council office, 2015. Available: http://www.gov.cn/zhengce/content/2015-05/17/ content_9776.htm

14 National Health Commission of China.. The announcement of fully implementation of the public hospital reform, 2017. Available: http:// www.nhc.gov.cn/tigs/s3581/201704/0563e06eff4441ffa9772dc3 Ob487848.shtml

15 Wooldridge JM. Introductory Econometrics-A modern approach. 5 edn. USA, Mason: South-Western Cengage Learning, 2003.

16 Autor DH. Outsourcing at will: the contribution of unjust dismissal doctrine to the growth of employment outsourcing. J Labor Econ 2003;21:1-42.

17 Chen Q. Advanced econometrics \& stata applications. 2 edn. Beijing: Advanced Education Publishing House, 2014. 
18 Shi X, Zhu D, Man X, et al. "The biggest reform to China's health system": did the zero-markup drug policy achieve its goal at traditional Chinese medicines county hospitals? Health Policy Plan 2019;34:483-91.

19 Beck T, Levine R, Levkov A. Big bad banks? the winners and losers from bank deregulation in the United States. J Finance 2010;65:1637-67.

20 Clemens F, Peichl A, Siegloch S. Do higher corporate taxes reduce wages? micro evidence from Germany. Am Econ Rev 2018;108:393-418.

21 Zhang G, Liu W, Bao H. Study on the time-lag effect of multiple environmental regulation policies on regional industrial structure change. J Manag Sci 2020;23:95-107.

22 Lv Y, Lu Y, Wu S. The Effect of the "Belt and Road Initiative" on Chinese corporate greenfield investment 2005-2016Based on the double difference estimation. Econ Research $J$ 2019;54:187-202.

23 Zhang $\mathrm{Y}$, Cheng $\mathrm{H}$, Wang J. The effect of implementation of the medicines zero mark-up policy in Chinese public hospitals: a systematic review. Chin J Evidence-based Med 2021;21:546-58.

24 Cheng $\mathrm{H}$, Zhang $\mathrm{Y}$, Sun J. Effect of implementation of the zero markup medicines policy in Chinese public hospitals: a meta-analysis. J Pharmaco-Epidemiol 2021;30:601-10.

25 Jiang X, He P, Zhu D, et al. Different impacts of the zero-markup drug policy on County general and traditional Chinese medicine hospitals: evidence from Shandong Province, China. Int J Equity Health 2020;19:219.

26 Wang X, Li F, Wang X, et al. Effects of different mark-up drug policies on drug-related expenditures in tertiary public hospitals: an interrupted time series study in Shanghai, China, 2015-2018. Biosci Trends 2020;14:16-22.

27 Yan K, Yang C, Zhang H, et al. Impact of the zero-mark-up drug policy on drug-related expenditures and use in public hospitals, 2016-2018: an interrupted time series study in Shaanxi. BMJ Open 2020;10:e037034.

28 Jia Q, Qian J, Shen Y. Research on application status of the National specification for medical service prices. Chin J Health Inform Manage 2019;16:163-6.

29 Wang J, Cui B, Wei X. The impact of separating drug sales from medical services on medical resource utilization and medical expense in Beijing: take inpatients with ischemic heart disease for example. Chin J Health Policy 2019;12:45-52.

30 Lu M, Guo Y. The impact of separating drug and medical service on the hospitalization expense of patients with medical insurance in pilot hospitals of Beijing. Chin Med Insur 2014;11:49-51.

31 Wang J, Cheng Z, Cui B. The impacts of separating drug sales from medical services pilots on inpatient expenditures in Beijing : A case study of five pilot tertiary hospital. China J Health Policy 2018;11:42-8.

32 Zhao F, Yang L, Zhang X. Effect of separating drug sales from medical services on hospital revenue and medical services in the County public hospitals of Guangxi Province. Chin J Heath Policy 2015;8.

33 The National Health Commission of China. The announcement of the 1st wave of pilots to implement the public hospital reform, 2010. Available: http://www.nhc.gov.cn/tigs/s10005/201002/aa5fd9e9118e 4c02a87d3bd249dddc5b.shtml

34 The National Health Commission of China. The announcement of the 2nd wave of pilots to implement the public hospital reform, 2014. Available: http://www.nhc.gov.cn/tigs/s3581/201405/e16bc82c7059 4c26902454fc97c7ec76.shtml

35 The National Health Commission of China. The announcement of the 3rd wave of pilots to implement the public hospital reform, 2015. Available: http://www.nhc.gov.cn/tigs/s3581/201505/3139dcfc7521 4280a376cd59dd0cf099.shtml

36 The National Health Commission of China. The announcement of the 4th wave of pilots to implement the public hospital reform, 2016. Available: http://www.nhc.gov.cn/tigs/s10006/201605/a9891a0b 7bab4c1bab0641d04395f86b.shtml

37 Zhai T, Chen C, Zhang L. Research on economic operation and financing policies of public hospitals under the normalization of pandemic prevention and control. Chin Health Econ 2021;40:65-7.

38 Zhang $\mathrm{X}$, Lai $\mathrm{H}$, Zhang $\mathrm{L}$, et al. The impacts and unintended consequences of the nationwide pricing reform for drugs and medical services in the urban public hospitals in China. BMC Health Serv Res 2020;20:1058.

39 The Government of China. The National Development and Reform Commission's opinion to deep the reform of pricing mechanism, 2017. Available: http://www.gov.cn/xinwen/2017-11/11/content 5238855.htm 